\title{
The Social and psychological impact of Covid-19 on the university students, a case study: University of Blida 2
}

\author{
Amel Beichi ${ }^{1}$, Osman Ahmed ${ }^{2}$, Tchalabi Sakina ${ }^{3}$ \\ ${ }^{1,2}$ Department of sociology, Ajman University,UAE \\ ${ }^{3}$ Faculty of Humanities and Social Sciences, University blida2, Algeria \\ *o.ahmed@ajman.ac.ae
}

\begin{abstract}
:
The study examines the social and psychological impact of the COVID -19 pandemic on university students in a number of variables related to daily activities, family relations, university student relations and psychological health. The study aimed to find out the effect of closure during the spread of COVID -19 on the psychological and social aspects of university students. The study was conducted from 1-26 November and a questionnaire was developed that was completed online using the Google Forms platform in order to reach the largest possible number of students. A random sample of students from the University of Blida 2 in Algeria was selected in the Faculties of Humanities and Economics, taking into account homogeneity. And the disparity in the university community. The sample size was 132 students.
\end{abstract}

The most important results of the study can be summed up in that there are no significant differences in the social and psychological impact of COVID -19 on students who were infected with the virus and who were not infected with regard to variables of daily activity and university relations, but we find that the closure has affected family relations and the mental health of people with Corona virus.

Keywords: Psychological health, COVID-19, Gender, University Students, lockdown

\section{Introduction:}

At the end of the year 2019, the world identified a new pandemic, it was thought at the beginning that it was just an epidemic which could be controlled, but COVID-19 exceeded all expectations and spread in a few weeks to become the most deadly pandemic in human history. The epidemic began in Wuhan, China, and the number of cases continued to increase inside and outside Wuhan, extending thereafter to (217) countries and territories around the world. (Https://www.worldometers.info/coronavirus), which made the rate of injuries and deaths to increase continuously. The number of infected persons reached more than 51 million cases around the world and more than one million deaths until November 12, 2020 (https://covid19.who.int).

Through these estimated and approximate statistics, it is possible to talk about the extent of psychological fear and the accompanying social changes among the affected and unaffected persons. Rumors, news and misinformation, at the beginning of the pandemic's spread. Caused a lot of anxiety and psychological and social problems.

This worrying situation has resulted concern in all countries which focused their attention in controlling the spread of the epidemic through total or partial closure measures, without paying attention to the side effects of the closure, which are 
represented in mental health and accompanying social changes (Ruiz-Roso M \& others B. 2020.). Quarantine has been widely used to limit the spread of covid-19 infection and protect the health of individuals, at various times (Sohrabi C \& others.2020 .( )Orla McBride,2020).

\section{The Problem of the Study:}

The closure measures imposed by the spread of the Covid-19 epidemic have affected many social, psychological and mental health changes, as the emotional reactions to the pandemic varied (Rubin G. J \& others. 2020), (Talevi D. \& others 2020) and (Jakovljevic M. 2020). Algeria is one of the countries affected by the initial closure measures, which are considered one of the most restrictive experiences and suspension of social life in the Arab region (https://alain.com/article/flights-flying-in-skies-of-algeria). Therefore, this study examines the effects of Covid-19 on some psychosocial variables for university students in Algeria.

\section{Questions of the study:}

Q1. What is the impact of Covid-19 pandemic on some psychosocial variables related to the variable of daily activities, social, family and university relations, and the mental health of the infected and uninfected university students?

Q2. Are there differences in the impact of Covid-19 on the psychological and social variables of university students that indicate gender variable?

Q3. Are there differences in the effect of Covid-19 on the psychological and social variables of university students that indicate psychological illness variable?

Q4. Are there differences in the influence of Covid-19 on the psychological and social variables of the university student that indicate the variable of the presence of a psychological disorder?

\section{Objective:}

The study aims to identify the effect of closure during the spread of Covid-19 on the psychological and social aspects of university students.

\section{Methodology:}

This study was conducted from November 1-26. A questionnaire was updated, according to the fivepoint Linker method, to be completed online using the Google Forms platform, so as to reach the largest possible number of students. Data was collected via the internet. The evaluation also included a section with information related to research, as well as the consent form of participating in the study. The questionnaire was divided into two parts. The first one included seven questions about the primary data.The second one included the five variables of the study, and the validity of the questionnaire was confirmed using the formula (Alpha Cronbach). By looking at the 
stability coefficients obtained, we find that they are acceptable and their value exceeds 0.60 in all variables.

A random sample of students from the University of Blida 2 in the College of Humanities and the College of Economics was selected, considering the homogeneity and disparity in the university community. The sample size was 132 students.

The research is based on the statistical analysis method using SPSS program. Descriptive statistics and the $\mathrm{T}$ test have been used to study the differences and alternative ofManWenty in cases where the conditions for the $\mathrm{T}$ test are not met.

\section{Brief Literature Review:}

Numerous previous studies revealed the psychological and social impact of epidemics during previous pandemics, whether at the individual or group level. At the individual level, people are likely to suffer from fear of illness or death, but at the group level, it is a feeling of helplessness and stigma (Van Bortel,2016) .

This pandemic has also created fertile ground for many other psychological disorders, such as depression and anxiety (Holmes E. A \& others. 2020). A recent review of the psychological impact of quarantine, due to epidemiology, indicated that there are high rates of negative psychological effects among the public, including post-traumatic stress symptoms, persistent depression, great anger, panic attacks, and suicide (Liu T., Chen X. , Miao G. 2003 \& Maunder R., Hunter J. 2003 \&Brooks S. K. 2020). A March 2020 online survey of Mazza C. \& others showed that the prevalence of negative psychological symptoms is more related to the female gender than male gender, while a history of psychological problems and medical problems was associated with higher levels of anxiety and depression. This is what this study relied on in defining its objectives in the study sample.

Some studies, for example (Torales. J et al, 2020), have shown that one cannot ignore the risks that the closure has created for psychological health, especially in the exceptional circumstances of Covid-19. These circumstances left many problems, whether they appeared or may appear in the long run. The potential benefits of home quarantine were to be weighed against potential psychological problems, and then focusing on the attempt to mitigate the damage that the quarantine and the pandemic have left on psychological health. Both (Wang C. \& others.2020) and (Chong M \& others 2004) indicate that in such emergencies, the individual experiences a feeling of uncertainty about the future. Not only in health, but also in economic, social and political fields.

As a first step in combating any epidemic of infectious diseases in nature, it is important to assess the knowledge and awareness about this 
disease that have been reported by various studies in different population groups, including the study of both (Ahmed, M. A., J \& others 2020) and (Geldsetzer, P. 2020. Modi, P \& others 2020). This matter was absent in this case because of the ambiguity that accompanied the spread of Corona virus and its continuous development and the emergence of new symptoms at every stage, which led to many wrong ideas, negative feelings, fear, and interruption of relations and so on. This caused psychological and social harm to large sectors of society, including university students, in their studies, (Auerbach R.P \& others. 2016), (Bayram N, Bilgel N, 2008) and (Bruffaerts R $\&$ others, 2018) indicated this and concluded that the degrees of depression, anxiety and stress among students are higher than those among university employees. Some studies, such as (Wenjun Cao et al. 2020) referred to the psychological stress that the epidemic caused on university students in China, and the consequences of the general anxiety disorder. The study concluded that the student respondents suffer from severe anxiety, moderate anxiety, and mild anxiety. Moreover, the presence of relatives or acquaintances infected with COVID19 was a risk factor for increasing the anxiety of university students, which requires monitoring their psychological health during the spread of the epidemic.

\section{Analysis:}

To analysis of the variables and answer the study questions, as shown in the following tables:

Table 1:Determining impact of the COVID- 19 pandemic on daily activities by studying the differences between infected and uninfected university students.

Group Statistics / Independent Samples Testing

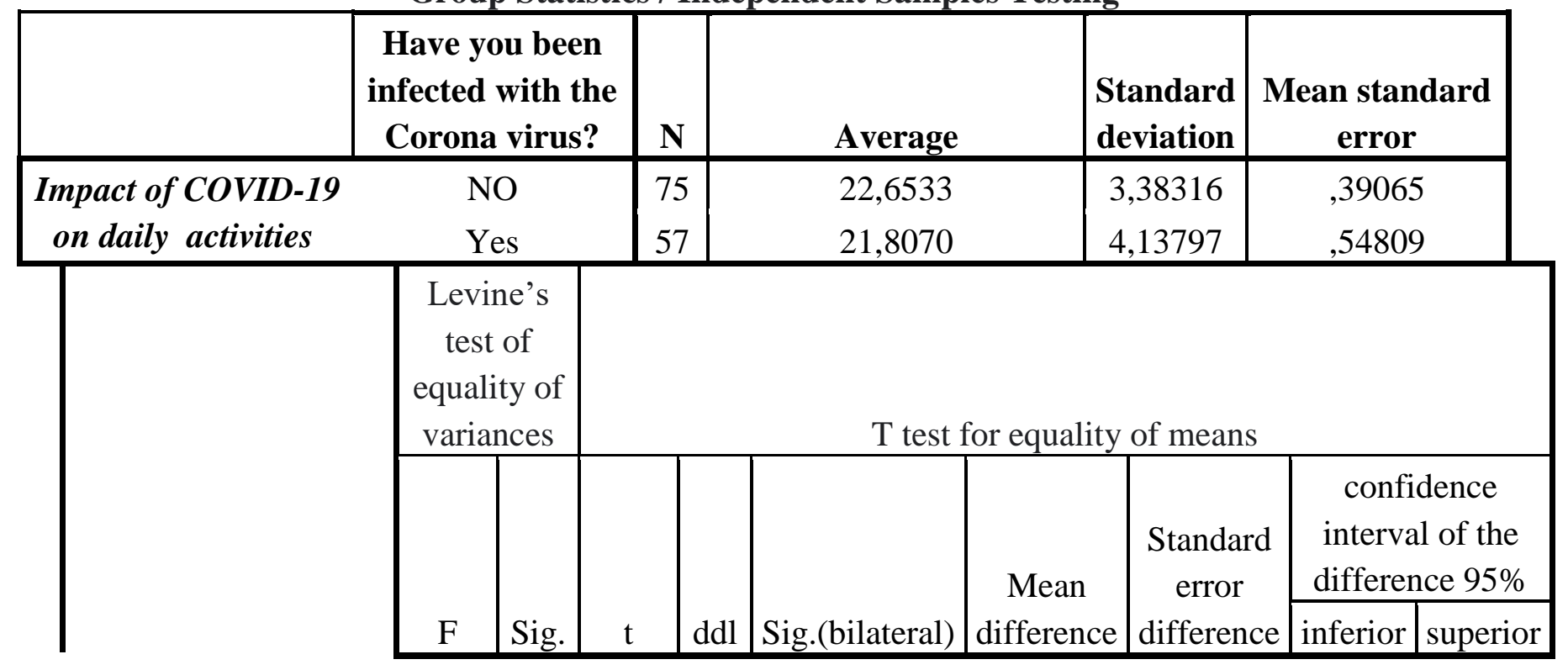




\begin{tabular}{|c|c|c|c|c|c|c|c|c|c|}
\hline $\begin{array}{cc}\text { Impact } & \text { Equal } \\
\text { of } & \text { variance } \\
\text { COVID- } & \text { assumption } \\
19 \text { on } & \\
\text { daily } & \\
\text { activities } & \end{array}$ & 2,011 &, 159 & 1,292 & 130 & ,199 & ,84632 & ,65492 & $\begin{array}{c}- \\
, 44937\end{array}$ & 2,14200 \\
\hline
\end{tabular}

Table No.1 shows that the number of studentsinfected with the COVID-19 pandemic is estimated at 57 out of 132 students, meaning that 75 students were not infected with it or did not show any symptoms because the current system in force in Algeria is to carry out examinations only if symptoms related to COVID-19 appear,such as fever, loss of sense of smell and taste, or dry cough and other symptoms.Through Table No., we find that there are no differences in the impact of the pandemic on daily life between those whowere infected with COVID-19and those who did and uninfected university students.

\begin{tabular}{|cc|c|c|c|}
\hline \multicolumn{5}{|c|}{ Ranks / Statistical Tests, } \\
\hline Have you been infected with the Corona virus? & N & Average rank: & Sum of ranks \\
\hline Impact of COVID-19 on family & NO & 75 & 72,40 & 5430,00 \\
relationships & Yes & 57 & 58,74 & 3348,00 \\
& Total & 132 & \\
\hline \multicolumn{5}{|c|}{ Impact of COVID-19 on family relationships } \\
\hline Mann-Whitney U test. & \multicolumn{4}{|c|}{3348,0000} \\
W from Wilcoxon & \multicolumn{4}{|c}{$-2,042$} \\
Z & \multicolumn{4}{|c|}{, 041} \\
\hline
\end{tabular}

a. Grouping variable:Have you been infected with the Corona virus? 
Table No. 2 shows that there is a difference in the average between the infected and the non-infected with respect to the variable of family relations, as we find that the average among the two patients was 72.40 compared to 58.74 for the non-infected, and we note that the difference tends in favor of those who did not have Covid-19, which indicates that the non-infected have strength inTheir family

Table3:impact of the COVID- 19 pandemic on social relationship by studying the differences between infected and uninfected university students.

\begin{tabular}{|lc|c|c|c|}
\hline \multicolumn{5}{|c|}{ Table NO.3 Ranks / Statistical Tests, ${ }^{\text {a }}$} \\
\hline Have you been infected with the Corona virus? & N & Average rank: & Sum of ranks \\
\hline Impact of COVID-19 on social & No & 75 & 71,42 & 5356,50 \\
relationships & Yes & 57 & 60,03 & 3421,50 \\
& Total & 132 & \\
\hline & \multicolumn{3}{|c|}{ Impact of COVID-19 on social relationships } \\
\hline Mann-Whitney U test. & \multicolumn{3}{c|}{1768,500} \\
W from Wilcoxon & 3421,500 \\
Z & \multicolumn{3}{|c|}{$-1,702$} \\
\hline
\end{tabular}

\section{a. Grouping variable: Have you been infected with the Corona virus?}

From the averages that appear in the table 3 , it becomes clear that there are statistical differences between the infected and the non-infected students in relation to the variable of social relations, as we find that the average absence of the epidemic was 71.42 , compared to the average of the disease was relationships during the spread of the epidemic, and the significant difference level of $(\alpha \leq 0.05)$ in the Mann-Whitney test, which is known to be the alternative to the "T" test, is used in the study of differences between two independent samples and is used in the event that one of its conditions is not checked. 
Table 4:impact of COVID-19 on university students relations:

\begin{tabular}{|c|c|c|c|c|}
\hline \multicolumn{5}{|c|}{ Ranks / Statistical Tests, ${ }^{a}$} \\
\hline \multicolumn{2}{|c|}{ Have you been infected with the Corona virus? } & $\mathbf{N}$ & $\begin{array}{l}\text { Average } \\
\text { rank: }\end{array}$ & $\begin{array}{l}\text { Sum of } \\
\text { ranks }\end{array}$ \\
\hline \multirow{4}{*}{$\begin{array}{c}\text { impact of COVID-19 on university student } \\
\text { relations }\end{array}$} & No & 75 & 68,20 & 5115,00 \\
\hline & Yes & 57 & 64,26 & 3663,00 \\
\hline & Total & 132 & & \\
\hline & \multicolumn{4}{|c|}{$\begin{array}{c}\text { impact of COVID-19 on university } \\
\text { student relations } \\
\end{array}$} \\
\hline Mann-Whitney U test. & \multicolumn{4}{|c|}{2010,000} \\
\hline W from Wilcoxon & \multicolumn{4}{|c|}{3663,000} \\
\hline $\mathrm{Z}$ & \multicolumn{4}{|c|}{,- 589} \\
\hline Sig. asymptotic (bilateral) & \multicolumn{4}{|c|}{, 556} \\
\hline
\end{tabular}

a. Grouping variable: Have you been infected with the Corona virus?

Table No.4 shows that the differences between the averages are close with respect to the variable of the impact of COVID-19 on university student relations, as the average for people with COVID- 19 reached 68.20, and the average for no infection was 64.26, which is a non-significant difference in
Mann-Whitney $U$ test Which means that there are no differences in university relations between those who were infected and did not have the COVID- 19 pandemic. This may be attributed to the adoption of remote study as an alternative to classroom study.

Table.5:impact of COVID-19 onPsychological health:

Ranks / Statistical Tests, ${ }^{\text {a }}$ :

\begin{tabular}{|c|c|c|c|c|}
\hline & $\begin{array}{c}\text { Have you been infected with the } \\
\text { Corona virus? }\end{array}$ & $\mathbf{N}$ & $\begin{array}{l}\text { Average } \\
\text { rank: }\end{array}$ & $\begin{array}{c}\text { Sum of } \\
\text { ranks }\end{array}$ \\
\hline \multirow{4}{*}{$\begin{array}{l}\text { impact of COVID-19 on } \\
\text { Psychological health }\end{array}$} & No & 75 & 42,69 & 3202,00 \\
\hline & Yes & 57 & 97,82 & 5576,00 \\
\hline & Total & 132 & & \\
\hline & \multicolumn{4}{|c|}{ impact of COVID-19 onPsychological health } \\
\hline \multicolumn{2}{|c|}{$\begin{array}{c}\text { Mann-Whitney U test. } \\
\text { W from Wilcoxon } \\
\text { Z } \\
\text { Sig.asymptotic (bilateral) }\end{array}$} & & $\begin{array}{l}000 \\
000 \\
10 \\
0\end{array}$ & \\
\hline
\end{tabular}

a. Grouping variable: Have you been infected with the Corona virus? 
Table No. 5 shows that there is a high difference in the averages associated tothe impact on Psychological health between infected and noninfected students, as we find that the average of students with Covid-19 and whose Psychological healthwas affected by injury was 97.82 , while we find that the average of students who did not have
COVID-19, this was reflected on their mental health, which reached 42.82 , which means that there is a clear impact on the Psychological healthof infected and uninfected students during the period of the Corona virus outbreak, and that this difference is significant in the Man-Whitney test.

Table6: Differences between the impact of the Covid-19 pandemic on the psychological and social variable are due to the gender of the university students:

\begin{tabular}{|c|c|c|c|c|}
\hline \multicolumn{5}{|c|}{ Ranks / Statistical Tests, ${ }^{\mathrm{a}}$ : } \\
\hline & GENDER & $\mathbf{N}$ & Average rank: & Sum of ranks \\
\hline \multirow[t]{4}{*}{ impact of COVID-19 on psychosocial } & M & 65 & 41,26 & 2682,00 \\
\hline & $\mathrm{F}$ & 67 & 90,99 & 6096,00 \\
\hline & Total & 132 & & \\
\hline & \multicolumn{4}{|c|}{ impact of COVID-19 on psychosocial } \\
\hline Mann-Whitney U test. & \multirow{4}{*}{\multicolumn{4}{|c|}{$\begin{array}{c}537,000 \\
2682,000 \\
-7,471 \\
, 000\end{array}$}} \\
\hline W from Wilcoxon & & & & \\
\hline $\mathrm{Z}$ & & & & \\
\hline Sig.asymptotic (bilateral) & & & & \\
\hline
\end{tabular}

\section{a. Grouping variable :Gender}

It is noted from Table No. 6 the high average of females in terms of the psychosocial impact of the Corona pandemic on university students, as opposed to the average for males, where females swallowed 90.99 and males reached 41.26, this difference is significant in the Mann Whitney test.
There are many studies that have shown that the differences are related.Gender in the psychological impact during COVID-19 epidemic lockdown period, such as, (B. Ausín, et al, 2020) (Ayesha Shahid, et al, 2020) 
Table7:The effect of COVID-19on the differences between infected and uninfected for the psychosocial variable:

Group Statistics / Independent Samples Testing

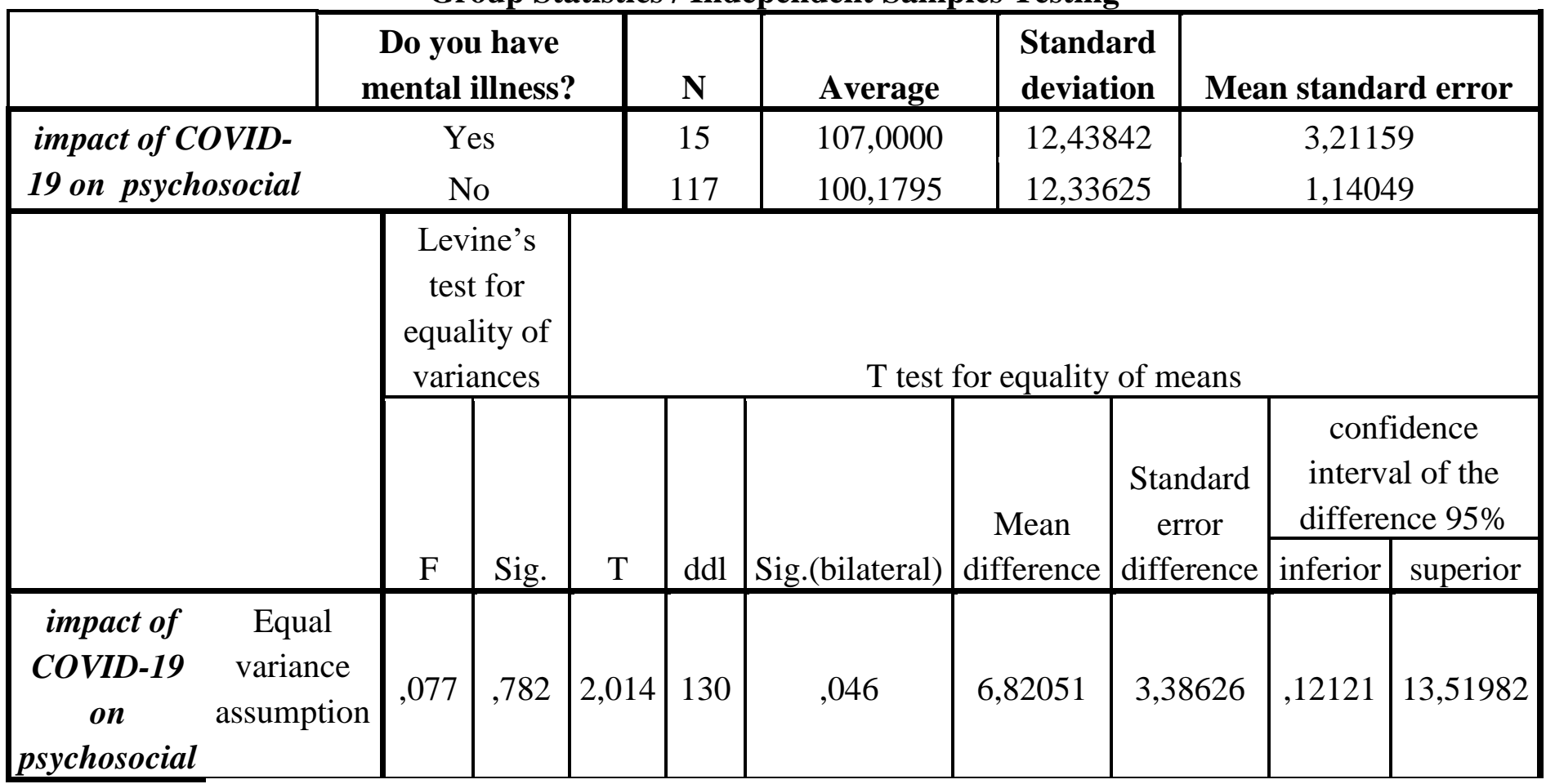

Table No. 7 shows that the T-test value was 2.01, which is a significant value at the level of significance $(\alpha \leq 0.05)$ which means that there are significant differences between those suffering from a mental disorder and those without mental

Table.8:differences between the infected and the non-infected with mental illness and the correlation of the impact of the COVID-19 pandemic on the psychosocial variable

\section{Ranks / Statistical Tests, ${ }^{\text {a }}$}

\begin{tabular}{|c|c|c|c|c|}
\hline & $\begin{array}{c}\text { Do you have mental } \\
\text { illness? }\end{array}$ & N & $\begin{array}{c}\text { Average } \\
\text { rank: }\end{array}$ & $\begin{array}{c}\text { Somme des } \\
\text { ranges }\end{array}$ \\
\hline impact of COVID-19 on & No & 84 & 57,91 & 4864,50 \\
psychosocial & Yes & 48 & 81,53 & 3913,50 \\
& Total & 132 & \\
\hline
\end{tabular}




\section{Mann-Whitney U test. \\ $\mathrm{W}$ from Wilcoxon}

$\mathrm{Z}$

Sig.asymptotic (bilateral)
1294,500

4864,500

$-3,415$

\section{a. Grouping variable: Do you have mental illness?}

Table 8 shows that the value of " $z$ " in the MannWhitney test is significant. Which means that the differences between the averages are significant, as the average for those who have a mental illness when the psychosocial effects of the COVID-19 pandemic reached 81.53, which is an average greater than the average for those without mental illnesses, as it reached 57.91. This indicates that the psychosocial effects of the pandemic are greater for those who have chronic diseases psychological.

\section{Results \& Discussing:}

It is important to note that the study period was completed in November 2020, when the Algerian state has amended laws related to the closure of imposing home quarantine from 08:00 PM until 05:00 AM, and allowed students to return to study classes to take exams that had previously been suspended due to the pandemic.

The results of this study showed that there were no significant differences between those who were infected by COVID-19 and those who were not, with regard to the effect of virus infection on daily activities of Blida 2 University students. Perhaps this is due to the absence of symptoms of the epidemic on student group.
This situation is also found in the variable impact of COVID-19 on social relations and student relations within the university. This does not mean that the pandemic has not affected the pattern of university or social relations, but on the contrary, these relationships have been affected by the epidemic as indicated by many studies and statistics (Brooks SK \& others. 2020) and (Taylor MR et al, 2008.). It is clear that the pattern of these relationships for university students has taken a new form due to the closure and the shift to virtual study.

While Covid-19 infection affected the student family relationships, it also created differences between the infected and the uninfected in their family relationships. Differences were found among them in favor of those who were not infected, with an average of 72.40, meaning that their relationships were stronger and better, unlike the infected whose average was 58.74 especially that at the level of significance $(\alpha \leq 0.05)$ this shows that their family ties were affected. This is somewhat self-evident, as the student in Algeria lives with his/her family, and therefore $\mathrm{s} / \mathrm{he}$ is in a daily contact with them and his/her infection leads to reducing this contact so that s/he must be put in 
quarantine in his/her room for fear of transmitting the infection to his/her family.

The results of the study also show that the effect of the infection with Covid-19 on the psychological health of students; so that 57 of those who were infected, had an average of a variable on the impact of COVID-19 on psychological health 97.82; compared to that of 75 students who were not infected, their average for this variable was 42.69 at a level of spiritual indication 0.01. This is largely expected, due to the severe closure, fear of disease and its consequences, and the increase in the severity of symptoms in some patients; in addition to the psychological problems already existed in some adolescents (A. Chevance. 2020,). Therefore, the incidence of COVID-19 is considered to be a catalyst and supportive factor for the deterioration of psychological health. In general, previous studies indicated that psychological health has been severely affected by the spread of previous epidemics (Sim K., Chua H.C. 2004, Wu P \& others 2009).

This study also shows the difference between genders in terms of the psychosocial effects of Covid-19. There is a difference in favor of females. The average of 67 women students was estimated at 84.82 , while the average of 65 men students was estimated at 47.62 , which is a significant difference of 0.01 . Females are affected psychosocially much greater than males. This is due to the nature of women and the peculiarities of their personality.
Studies have documented differences between women and men with regard to symptom reporting, treatment seeking, coping strategies and many neurobiological variables related to depression. It has been shown that women are twice as likely as men to develop depression and experience stress, in addition to providing less flexibility (Wellman C. L, et al, 2008.). Depression symptoms were among the most common psychological symptoms among women population of China in the first two weeks after the outbreak as indicated by (C Wang, et al, 2020). It was also observed, among the general Italian population, that higher levels of psychological problems were reported from females compared to their male counterparts (Hao F. \& others 2016. Rossi R. 2020). This is not only related to this pandemic, but it has also been shown that females are generally more vulnerable to distress, depression and anxiety (Lim GY. 2020) (Chong et al. 2004).

With regard to students suffering from a psychological disorder, there were differences between them and those who did not suffer from any psychological disorders, in terms of the variable of the psychosocial effects of Covid-19. Although only 15 students suffer from psychological disorders compared to 117 students who do not suffer, however, the differences in the psychosocial effects of COVID-19 were at the level of significance $(\alpha \leq 0.05)$ in the $(\mathrm{T})$ test, indicating that 
the effect of COVID-19 on the psychosocial state of those who suffer from a psychological disorder is greater than that of those who do not suffer. Therefore, the average effect was estimated for those who suffer by 107, while it was estimated at 100.17 for those without any disorders. Interestingly, individuals with "high health anxiety" (potential patients of general anxiety disorder, obsessive-compulsive disorder) are more likely to misinterpret simple and non-serious physical symptoms as evidence of serious illness. For example, they may misinterpret muscle pain or coughing as a symptom of COVID-19 infection. This in turn may increase their anxiety and suffering, and affect their behavior and decisionmaking ability (Asmundson GJG, Taylor S. 2020). Therefore, some studies, for example (Shigemura J. \& others. 2020, Lima CKT, \& others 2020 Zandifar A. 2020, Badrfam R. Iranian,) came to identify the various possible ways in which "Covid-19" epidemic will affect psychological health in the world.

We find that this is similar to those who suffer from chronic disease, as the study of (Wang C, el al, 2020) proved that they suffer from greater stress in terms of psychosocial aspect. This is also proved by this study, therefore, the study of differences in terms of the psychosocial effects of COVID-19 between those with a chronic disease and those without a chronic disease is a significant difference in the Mann-Whitney test. So, the World Health Organization has issued specific psychosocial considerations to reduce the growing stigma caused by COVID-19 pandemic

(https://www.who.int/docs/defaultsource/coronaviruse/mental-health-considerations.pdf).

\section{Conclusion:}

COVID-19" pandemic has prompted most countries to take social isolation measures as a way to control the spread of the virus although significant psychological and social effects of home quarantine have been indicated in previous experiments. However, there were not many options, with the significant increase in the number of daily cases and the rapid spread of this epidemic, so that it would develop into a pandemic in a very short period of time. Consequently, physical safety had priority over psychosocial health, which caused many damages at the relational, socio-psychological level, as it is evident in the results of this study which is similar to several studies referred to in this study.Mass hysteria and rapidly spreading panic regarding COVID-19 may lead to a paradigm of new psychosocial concepts accompanying all types of life among college youths that could be more harmful in the long term than the virus itself. Therefore, the study concludes that attention should be given to university youth category, as they are active groups in various aspects of life, and the positive foundation of a virtual life model in such a way that the quality of life and the quality of real social relations cannot be lost. Therefore, attention should be paid to not separating the psychological 
and social aspects in revealing the effects of the emerging pandemic on university students, and recommending more joint studies with an intellectual, psychological, physical, and sociocultural approach to absorb the effects of this pandemic on general students.

\section{Reference:}

[1] A. Chevance etal,(2020) Assurer les soins aux patients souffrant de troubles psychiques en France pendant l'épidémieà SARS-CoV-2

[2] Asmundson G.J.G., Taylor S ,(2020) How healthanxiety influences responses to viral out breakslike COVID-19: what all decisionmakers, healthauthorities, and health care professionnels need to know. J AnxietyDisord, v.71, doi: 10.1016/j.janxdis.2020.102211

[3] Ayesha Shahid, et al,(2020), Evaluation of psychological impact, depression, and anxiety among pregnant women during the COVID-19 pandemic in Lahore, Pakistan, International Journal of Gynecology, V.151(3),p.p 463-465.

[4] B. Ausín, et al, (2020), Gender-related differences in the psychological impact of confinement as a consequence of COVID-19 in Spain, Journal of Gender Studies, V.9(8), p.p38 ,

[5] Brooks SK, et al. (2020), the psychological impact of quarantine and how to reduce it: rapid review of the evidence. V.395 (10227),p.p912-920.
[6] C.Wang,et al(2020)A longitudinal study on the mental health of general population during the COVID-19 epidemic in China, Brain, Behavior, and Immunity journal, v.87,p.p4048.

[7] C Wang et al,(2020),Immediate psychological responses and associated factors during the initial stage of the 2019 coronavirus disease (COVID-19) epidemic among the general population in China, In. J. Environ Res Public Health. V.17(5),https://doi.org/10.3390/ijerph17051 $\underline{729}$

[8] Chong, et al. (2004). Psychological impact of severe acute respiratory syndrome on health workers in a tertiary hospital, The British Journal of Psychiatry,v.185(2), p.p 127-133.

[9] HaoF,et al (2020). Do psychiatric patients experience more psychiatricsymptomsduring COVID-19 pandemic and lockdown? A casecontrol studywith service and research implications for immunopsychiatry. Brain ,Behavior, Immun. V.87,p.p 100-106.

[10] Lim GY.,( 2018),Prevalence of depression in the community from 30 countries between 1994 and 2014. Scientific Reports. p.p 3-8.

[11]Lima C.K.T et al, (2020), The emotional impact of Coronavirus 2019-nCoV (new Coronavirus disease), Psychiatr Res journal. V.287(112915), https://doi.org/10.1016/j.psychres.2020.112915, 
[12] Nayak A. S et al, (2019),Gender variability of perceived stress and negative inferential feedback in depression. Indian, Journal of Psychological Medicine,v. 41(4), p.p331-337.

[13] Orla McBride,et al,(2020), Monitoring the psychological impact of the COVID-19 pandemic in the general population: an overview of the context, design and conduct of the COVID-19 Psychological Research Consortium (C19PRC) Study, Overview of C19PRC Study, v2_13,p.p8-15

[14] Rossi R., et al. (2020). COVID-19 pandemic and lockdown measures impact on mental health among the general population in Italy. medRxiv 11:790.

10.3389/fpsyt.2020.00790 .p.187.

[15]Shigemura J.et al(2020), Public responses to the novel 2019 coronavirus (2019-CoV) in Japan: mental health consequences and target populations. PsychiatrClinNeurosci journal,v.74(4),p.p 281-282,

[16]Sim K., Chua H.C.(2004) The psychological impact of SARS: a matter of heart and mind. CMAJ,V. 170,p.p811-812.

[17]Taylor MR et al,(2008), Factors influencing psychological distress during a disease epidemic: data from Australia's first outbreak of equine influenza. BMC Public Health journal. V.8 (1) p.8.
[18]Wellman C. L. et al, (2018). Sex differences in risk and resilience: Stress effects on the neural substrates of emotion and motivation. Journal of Neuroscience: v.38 (44),p.18. 